\title{
Challenges Faced by Female Healthcare Professionals in the Workforce: A Scoping Review
}

This article was published in the following Dove Press journal:

Journal of Multidisciplinary Healthcare

\author{
Abdullah Mohammed \\ ALobaid $\mathbb{D}^{1,2}$ \\ Cameron McR Gosling (1D' \\ Eihab Khasawneh $\mathbb{D}^{1,3}$ \\ Lisa McKenna $\mathbb{D}^{4}$ \\ Brett Williams (D) \\ 'Department of Paramedicine, Monash \\ University, Melbourne, Victoria, \\ Australia; ${ }^{2}$ Prince Sultan bin Abdulaziz \\ College for Emergency Medical Services, \\ King Saud University, Riyadh, Kingdom of \\ Saudi Arabia; ${ }^{3}$ Faculty of Applied Medical \\ Sciences, Jordan University of Science and \\ Technology, Irbid, Jordan; ${ }^{4}$ La Trobe \\ University, School of Nursing and \\ Midwifery, Melbourne, Victoria, Australia
}

Correspondence: Abdullah Mohammed ALobaid

Department of Community Emergency Health \& Paramedic Practice, Monash

University, Monash University-Peninsula

Campus, McMahons Road, Frankston,

Melbourne, Victoria, Australia

Tel +6 I 4I I I I2042

Email a.alobaid33@gmail.com
Background: The number of women entering the medical and healthcare workforce globally has increased in the past several decades. Women have many roles and positions in healthcare organizations, hospitals and healthcare education settings. Although there has been an increase in the number of women, female workers continue to face many workplace challenges. This scoping review aimed to explore the challenges female healthcare professionals face in the workforce.

Methods: A scoping review utilizing Arksey and O'Malley's six-step framework was undertaken to identify and map available literature addressing challenges faced by female healthcare professionals in the workforce. The databases searched included Embase, EmCare, Medline, Cumulative Index of Nursing and Allied Health Literature (CINAHL) and Business Source Complete (BSC). Additional searches were performed using Google Scholar, Trove and grey literature.

Results: The initial search yielded 2455 publications (Medline $n=369$; EmCare $n=276$; Embase $n=612$; CINAHL $n=1088$; Business Source Complete $n=109$; mixed grey literature $n=1$ ). After removal of duplicates, 1782 citations remained. Abstract and title screening reduced the field to 36 publications, following which full-text reviews were conducted. Consensus was reached on 16 publications for final review. After analyzing the articles, three themes were identified: i) family responsibilities, ii) workplace environment and iii) stereotyping.

Conclusion: Findings confirm that female healthcare professionals face circumstances that may affect their family lives, as well as factors relating to the workplace environment and stereotypes. Implementing strategies such as reduced work hours, flexible timing and parttime work can support women in the workplace, which then enhances and supports gender equality in healthcare organizations.

Keywords: female, healthcare providers, family responsibilities, workplace, stereotype

\section{Introduction}

The number of women entering the medical and healthcare workforce globally has increased over the past several decades. ${ }^{1}$ In Australia, $79 \%$ of people employed in the healthcare and social assistance workforce are women, ${ }^{2}$ while in the United States (US) $78.4 \%$ of workers in the healthcare and social assistance workforce are women. ${ }^{3}$ Of note is that female healthcare professionals are distributed unequally across different clinical professions such as medicine, nursing and physiotherapy. For example, in the United Kingdom (UK) more than $89.4 \%$ of the nursing and midwifery workforce is female, ${ }^{4}$ and $93 \%$ of nurses in the US are female, ${ }^{5}$ while in Canada it is reported that $41 \%$ of physicians are female ${ }^{6}$ and just over one-third of Australian doctors are women. ${ }^{7}$ 
Women have many roles and positions in healthcare organizations, hospitals and healthcare education settings, ${ }^{8}$ such as doctors, nurses, midwives and administrators. ${ }^{9,10}$ For example, Petek et al ${ }^{11}$ reported that $65 \%$ of doctors in Slovenia were women and the ratio of male to female in general practice was 1:5, while in Latvia the percentage of female doctors was $74.3 \%{ }^{12}$ Treister-Goltzman and Peleg $^{13}$ reported that females' jobs in hospitals were located in all important areas, such as laboratories and radiological departments. However, figures from the UK National Health Service (NHS) showed that women held only $36 \%$ of senior positions in pharmacy departments (where $61 \%$ of pharmacists are female), which means gender equality has not been reached. ${ }^{14}$ Batchelor $^{14}$ claimed that the importance of diversity in the workplace should facilitate all staff being able to balance their careers with their family life, regardless of gender.

Female healthcare workers globally continue to face many challenges in the workplace ${ }^{15}$ such as family duties, poor human resource policies and gender inequalities that hinder their professional growth. ${ }^{13,15-17}$ Work-family balance was highlighted as a significant barrier to career advancement in many countries. For example, Azeem and Akhtar ${ }^{18}$ reported that the perception of work interfering with family life was negatively related with work commitment $(r=-.681, p=0.001)$ and job satisfaction $(r=$ $-.488, \mathrm{p}=0.001$ ) among Indian healthcare workers; for $46 \%$ of women their commitment to their job was impaired and for $24 \%$ job satisfaction was affected by work interfering with family life.

According to Desai et al ${ }^{19}$ and Hong Lu et al, ${ }^{20}$ women in health fields face challenges related to poor work environments, which include unequal pay, unsatisfactory working conditions, limited opportunities for career advancement, work-related stress and unfavorable policies that promote patriarchy. Moreover, Desai et $\mathrm{al}^{19}$ reported that women in the US earned less than their male counterparts despite having equal output, amount of work, academic qualifications and experience. Examples of this have been detailed by female nurses, who have reported dealing with unfriendly workplaces that present few opportunities to advance their careers, as well as experiencing work-family balance challenges that hinder career progress and affect their lifestyle causing stress and excessive tiredness. ${ }^{21-23}$ A systematic review of gender differences in surgical skills acquisition reported that gender-related differences were more pronounced among medical students. ${ }^{24}$ Future surgical curricula needed to consider tailoring personalized programs that accommodated more mentoring and one-on-one training for female physicians. ${ }^{24}$

To our knowledge, there is no recent comprehensive literature review undertaken to collectively explore challenges faced by female healthcare professionals around the world. Therefore, a scoping review was conducted to explore these challenges.

\section{Methods}

A scoping review is using manual search to identify and map available literature on a selected topic. In this scoping review, the researchers used the six methodological steps described by Arksey and O'Malley. ${ }^{25}$ The steps are: 1) identify the research question; 2) identify relevant studies; 3) select studies; 4) chart the data; 5) collate, summaries and report the results; and 6) consult experts. The scoping review approach systematically maps and reviews existing literature on a selected topic, ${ }^{26}$ including literature from peer-reviewed and non-peer reviewed literature or grey literature.

\section{Identify the Research Question}

The research question guiding the scoping review was: What challenges do female healthcare professionals face in the workforce?

\section{Identify Relevant Studies}

Five databases were used to search for relevant articles: Medline, EmCare, Embase, Cumulative Index of Nursing and Allied Health Literature (CINAHL), and Business Source Complete (BSC). Additionally, we searched the following websites: Google Scholar www.scholar.google.com, Trove www.trove.nla.gov.au and the grey literature website www.greylit.org. The search strategy used a list of $\mathrm{MeSH}$ terms and keywords and was verified by an expert librarian (Table 1). We limited our search strategy to English language studies. The searches resulted in 2455 records, which were exported to EndNote X8 for screening.

\section{Study Selection}

Articles were considered for inclusion if they met the following criteria: 1) quantitative, qualitative or mixedmethod in design; 2) addressed challenges or obstacles faced by female healthcare professionals in the workforce in any healthcare-related discipline; 3) full-text peerreviewed articles reported in English language.

We excluded articles that had unsuitable study designs such as systematic reviews, scoping reviews, editorials and 
letters to the editor. The search yield from the databases was: Medline $(n=369)$, EmCare $(n=276)$, Embase $(n=612)$, CINAHL $(n=1088)$, BSC $(n=109)$, and mixed grey literature $(n=1)$. After the removal of all duplicates $(n=673)$ and irrelevant studies and reviewing all relevant abstracts, the selection process was conducted at two levels: title and abstract review and full-text review. The titles and abstracts of selected studies were independently screened (AMA and EK) based on the inclusion criteria. In the second stage, the full text of potentially eligible studies $(n=36)$ was assessed and inclusion confirmed by two authors (AMA and BW). The resulting 36 articles were reviewed again by both authors and further 20 articles were excluded following discussion surrounding the inclusion criteria. The remaining 16 articles were included in the scoping review. A PRISMA flowchart of article selection is presented in Figure 1.

\section{Charting the Data}

This stage of the Arksey and O'Malley framework allows data extraction from included studies for more descriptive data. A narrative review method was used to extract the data from each study. Narrative reviews summarize studies from which conclusions can be drawn into more holistic interpretations. $^{27}$ The data included: author and year of publication, country the study was conducted in, area of the study, study design or type, sample size, and results and themes emerging from the study. After full-text review and synthesis of the 16 articles, three themes emerged: i) family responsibilities, ii) workplace environment and iii) stereotyping.

\section{Collating, Summarizing and Reporting Results}

The data extracted from the included studies are reported in Table 2. It presents data on the different findings, explaining workforce challenges facing women in healthcare. Key outcome data from each of the included studies are presented as well as some of the challenges and barriers that women face to be a member of the healthcare workforce. Family responsibilities, workplace environment and stereotyping were the themes extracted from the analysis.

\section{Consultation (Optional)}

Two experts were contacted by email to provide any input to ensure there were no other studies missed. Neither expert suggested any additional literature.

\section{Discussion}

This scoping review explored the challenges faced by female healthcare professionals in the workforce. These will be discussed in three broad themes: challenges faced in balancing work and family responsibilities; challenges faced due to workplace issues such as lack of supportive policies and gender equality; and challenges faced in stereotyping of working women. All 16 reviewed articles mentioned these common challenges and confirmed that they were present and commonly experienced by female healthcare workers. Therefore, although the percentage of women joining the healthcare workforce has increased over recent years, ${ }^{28,29}$ female workers still face many impediments in their work lives that have a negative impact on their quality of life at work and at home. ${ }^{30}$

The scoping review clarifies that challenges are not mutually exclusive and often overlap. This may suggest that a lack of effective policies (workplace environment) often breeds stereotyping issues against working women and disrupts their work-life balance (family responsibilities). Although most of the studies were categorized under the theme of "workplace environment" and comparatively fewer studies categorized under "family responsibility" and "stereotyping", they are all thematically interlinked.

\section{Family Responsibilities}

The four articles thematically listed under family responsibilities' were undertaken in the UK, the US and Egypt in medicine and in Nigeria in medicine and nursing. These articles were tied with a singular idea that women health professionals struggle to balance their work and home, being torn between opposing expectations of their professions and family duties. For example, Adisa et al. ${ }^{31}$ conducted semi-structured interviews with Nigerian female doctors and nurses and identified how most (95\%) acknowledged the negative impact of their profession on their family lives in a patriarchal society. Adisa et $\mathrm{al}^{31}$ described how Nigeria's male-dominated society did not welcome the idea of women working professionally and, even if they did, that work should not come ahead of family priorities. The authors also noted that Nigerian women had to face domestic crises, family problems and social sanctions - such as humiliating behavior from relatives and family members - if they prioritized careers over familial duties. Another study by Farahat ${ }^{32}$ was conducted among female physicians in Egypt through selfadministered questionnaires that used open and closed 
Table I Search Strategy Including MeSH and Keywords

\begin{tabular}{|l|l|l|l|}
\hline $\begin{array}{l}\text { MeSH: } \\
\text { Challenges }\end{array}$ & $\begin{array}{l}\text { MeSH: } \\
\text { Female }\end{array}$ & $\begin{array}{l}\text { MeSH: } \\
\text { Healthcare } \\
\text { professionals }\end{array}$ & $\begin{array}{l}\text { MeSH: } \\
\text { Workforce }\end{array}$ \\
\hline $\begin{array}{l}\text { Keyword: } \\
\text { barriers } \\
\text { obstacles }\end{array}$ & $\begin{array}{l}\text { Keyword: } \\
\text { women } \\
\text { gender } \\
\text { woman }\end{array}$ & $\begin{array}{l}\text { Keyword: } \\
\text { healthcare professionals, } \\
\text { allied health, nurs*, } \\
\text { doctor*, physician*, } \\
\text { paramedic, } \\
\text { physiotherapy*, } \\
\text { occupational therapy*, } \\
\text { psychiatrist, laboratories*, } \\
\text { dentists* radiologist* }\end{array}$ & $\begin{array}{l}\text { Keyword: } \\
\text { workplace } \\
\text { career }\end{array}$ \\
\hline
\end{tabular}

Note: *Truncation.

questions to identify challenges of work-life conflict. The cohort reported not being able to afford time to specialize in their medical careers because they had to maintain child-rearing and housekeeping duties. ${ }^{32}$

The challenges faced by female healthcare professionals in Nigeria and Egypt were primarily sociocultural and in line with the stereotyping theme. Challenges faced by women in the UK and US were mostly related to stress in the workplace, including how medical institutions were under-prepared to meet the needs of pregnant physicians, sometimes even seeing program directors turning hostile towards their pregnant trainees. ${ }^{33}$

The Barnett and Gareis ${ }^{34}$ study of married female physicians with children $(n=104)$ comprised an online survey using the 38-item reduced-hours job-role quality scale and face-toface interviews. The main finding was that subjective reducedhours job-role quality was a significant predictor of life satisfaction, whereas the number of hours worked per se was not. Another report indicated that women could tailor their workload and hours based on their needs; for example, in Australia, pregnant women can discuss the issue with their employers and find solutions to reduce their work hours while pregnant. ${ }^{35,36}$

Barnett and Gareis ${ }^{34}$ presented two hypotheses - the scarcity hypothesis and the enhancement hypothesis - to decide the level of overall fulfilment for women physicians. The scarcity hypothesis was based on longer working hours, meaning less family time and low life satisfaction, whereas the enhancement hypothesis balanced work and family, which suggests women gain rewards and life satisfaction. ${ }^{34}$ This study drew favor for the enhancement hypothesis, although many of the women opted for reduced work hours to resolve their work-family conflict. This could perhaps be explained by the fact that all respondents had employed spouses and the study was based in a progressive developed country.

\section{Workplace Environment}

The studies grouped under the workplace environment theme were undertaken in the UK, the US (two articles), Canada, Japan (two articles), Australia, Slovenia, Germany and Ireland, and addressed the healthcare professions of medicine, nursing and radiology. Some articles discussed long working hours and female physicians looking for flexible work hours or part-time work in different professions such as nursing and medicine. ${ }^{37-42}$ However, Lane \& Piercy (2003) found that female nurses in the UK National Health Service faced major barriers in achieving fairness and equal opportunities in leadership because male managers deliberately behaved badly. For example, some managers disregarded female workers who spoke with them about unsatisfactory work that would lead to stressful environments in the workplace. Many leaders believed that women should not be allowed to progress into higher positions in their professions. ${ }^{43}$ The authors suggested that to attempt radical change would risk severe damage to the human infrastructure of the organization and hence its ability to effectively undertake its tasks. ${ }^{44}$

In addition to workplace issues, there are also issues related to stereotyping as identified in the scoping review themes. Gender stereotyping sometimes leads to selfsilencing by female healthcare professionals, who are demotivated to even speak in meetings. ${ }^{7}$ Price and Clearihan $^{7}$ attributed such self-silencing to lack of energy and confidence stemming from psychological repression in workplaces. Women are under-represented in leadership positions/roles in the healthcare system, including healthcare organizations. ${ }^{8,45,46}$ In Australia, where women now comprise more than one-third of the medical workforce, two factors may be restricting women's capacities to engage in leadership roles: energy limitations and lack of self-confidence. ${ }^{7}$ This means that female professionals need to increase their motivation, which will increase their energy and confidence to speak up. ${ }^{47}$

The presence of obstacles, such as inappropriate working-hour schedules, prevents women from working and getting jobs, ${ }^{42}$ which could have a substantial negative effect on female motivation to work effectively. ${ }^{39}$ There are strategies that reduce this effect, such as reduced/flexible work hours to help achieve balance with personal roles and supportive relationships with spouses and parents. Both strategies facilitate women's ability to be 


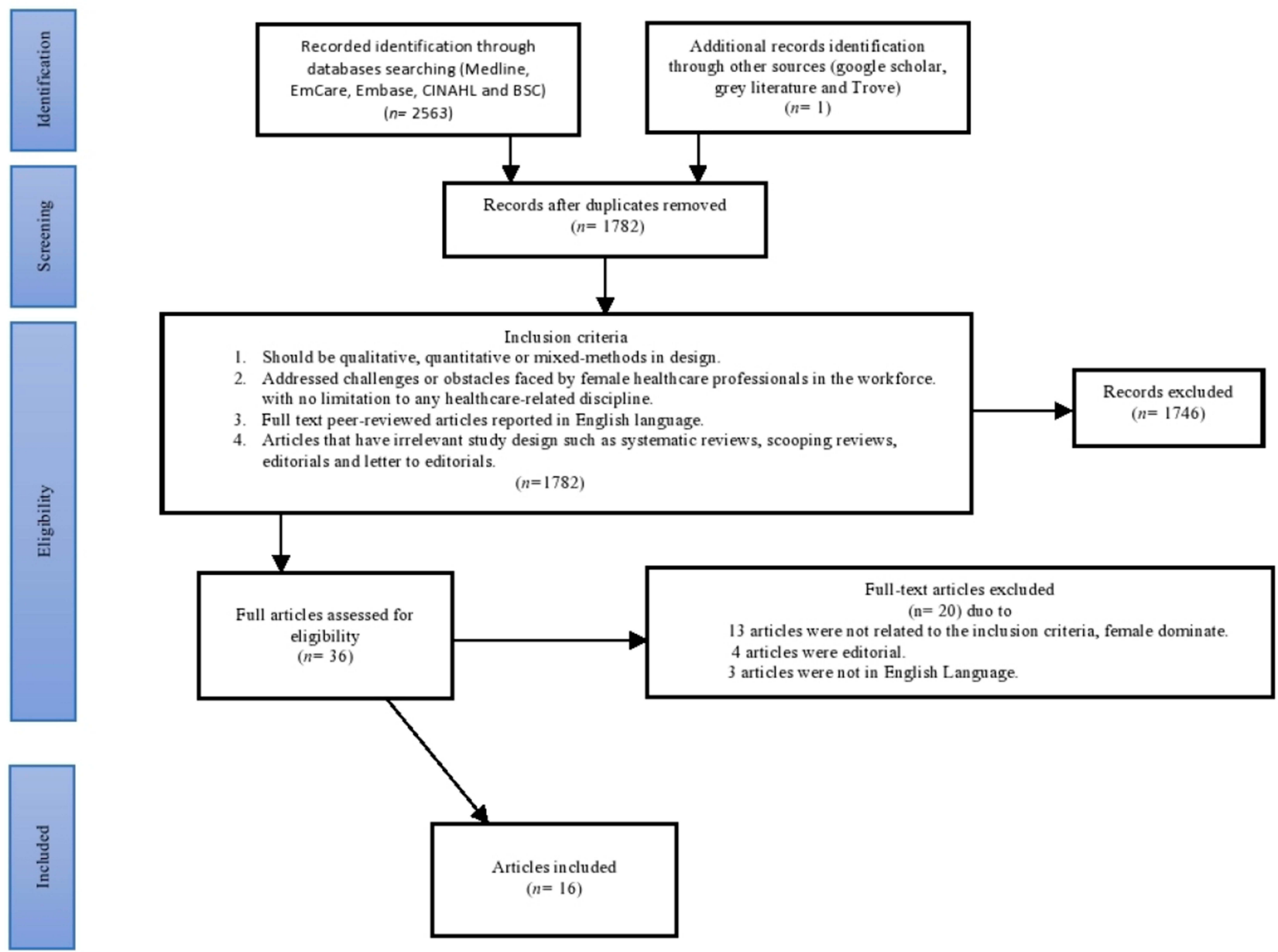

Figure I Flow chart of study selection.

available to their patients and maintain clear boundaries between personal and professional space, providing adequate time for parenting, recreation and rest. ${ }^{41}$

\section{Stereotyping}

Two articles addressed the stereotyping theme, Yamazaki et $\mathrm{al}^{48}$ and Tlaiss, ${ }^{49}$ and were undertaken in Japan in the medical discipline and Lebanon in medical and nursing disciplines, respectively. Stereotyping does not exist in isolation and is embedded deeply within sociocultural practices. ${ }^{50}$ While some societies and cultures, such as Japan and the Middle East, demonstrate greater conservatism in terms of female workforces, ${ }^{48,49}$ most western nations are open to the idea of women working. ${ }^{51}$

Tlaiss ${ }^{49}$ and Yamazaki et $\mathrm{al}^{48}$ studied obstacles that women faced in the Middle East and Japan. Tlaiss ${ }^{49}$ found that the healthcare sector in the Middle East would continue to under-represent women in the workplace due to cultural beliefs. For example, Saudi women believe that taking responsibility of kids and home while Saudi male taking care of income and expenses. ${ }^{52}$ In Japan, the cultural perspective on gender is influenced by society, family responsibility and work environment, which affects women's careers because of their culture and political representation. ${ }^{48}$ For example, Japanese women faced unprofitable income due to the government tax policies and company, so they prefer to be at home and the husband providing salary and benefits. ${ }^{53}$ Both nations are driven by patriarchal, masculine values, whereby domestic responsibilities should be a woman's foremost priority. ${ }^{54,55}$

Therefore, Tlaiss ${ }^{49}$ and Yamazaki et $\mathrm{al}^{48}$ reported that organizational barriers to female doctors were only an extension of larger socio-cultural expectations. To overcome these barriers, the researchers noted a need for external help (daycare, relatives, caregivers, etc.), although encouraging husbands to take on more responsibilities within the family was also helpful. ${ }^{48}$ Gender discrimination would never improve unless local government and 


\begin{tabular}{|c|c|c|c|c|c|}
\hline $\begin{array}{l}\stackrel{0}{E} \\
\stackrel{\Phi}{E} \\
F\end{array}$ & 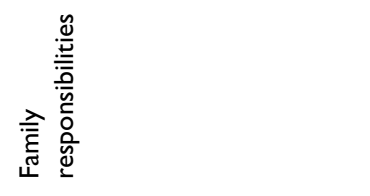 & 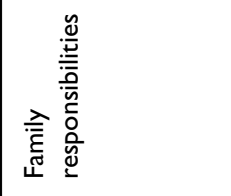 & 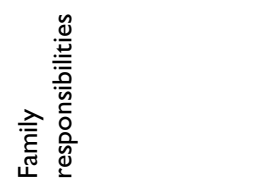 & 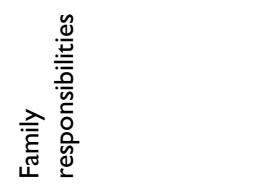 & 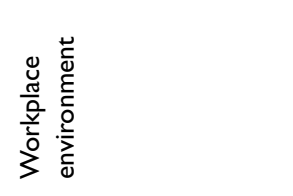 \\
\hline 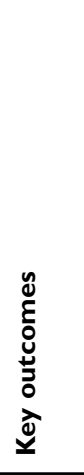 & 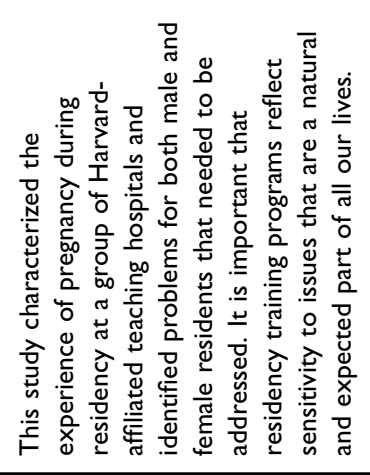 & 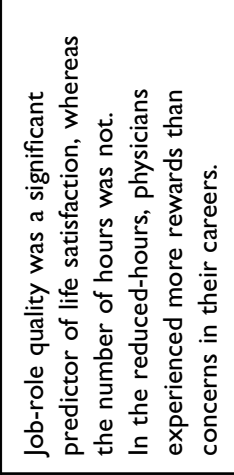 & 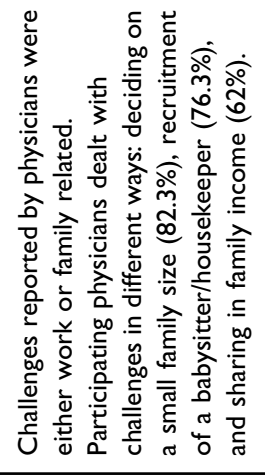 & 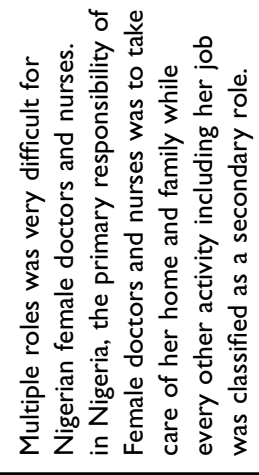 & 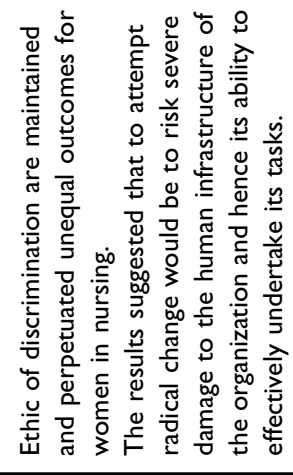 \\
\hline 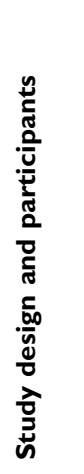 & 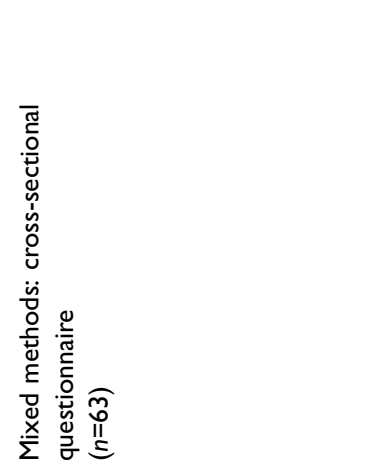 & 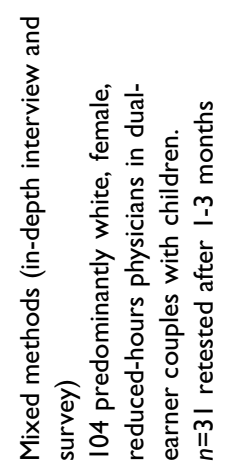 & 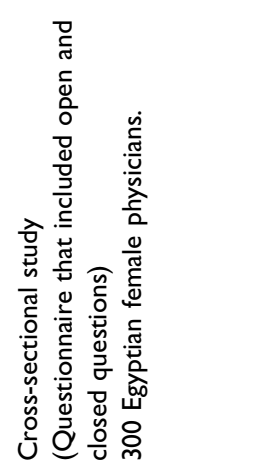 & 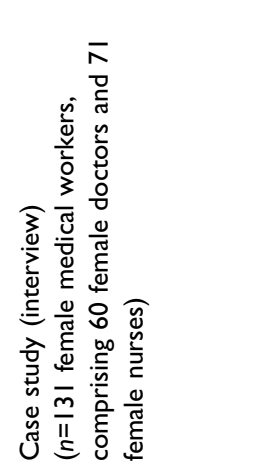 & 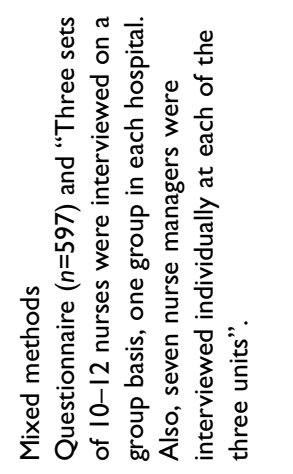 \\
\hline 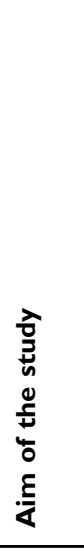 & 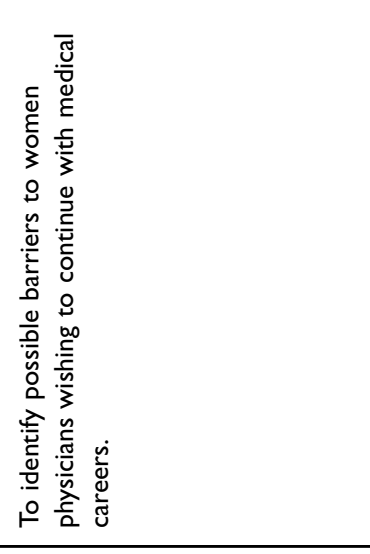 & 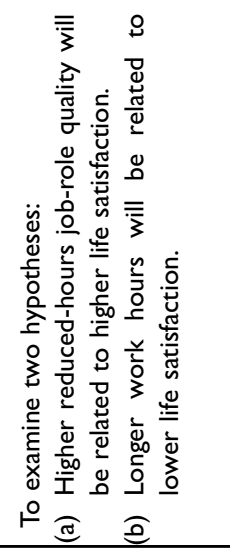 & 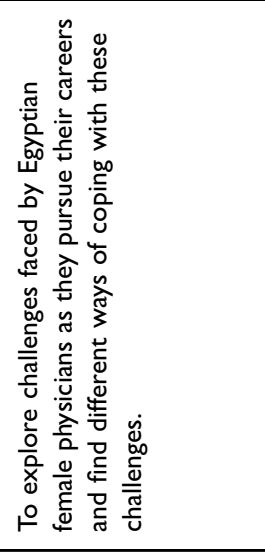 & 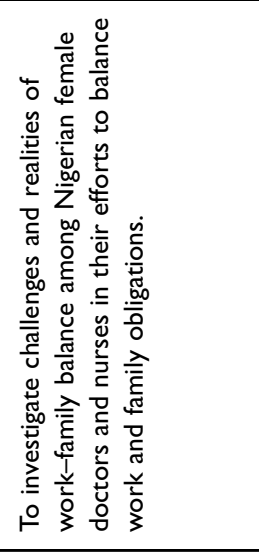 & 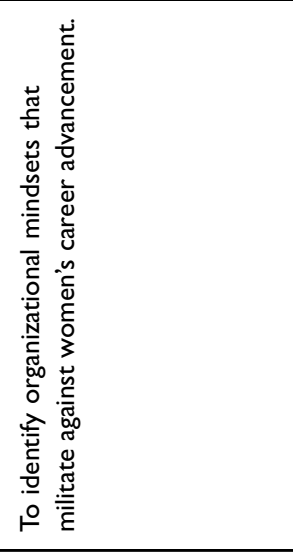 \\
\hline 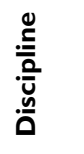 & 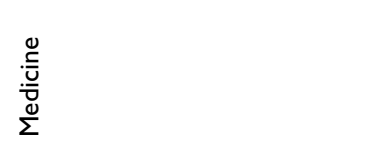 & 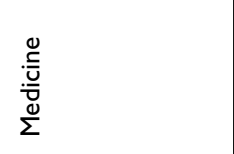 & 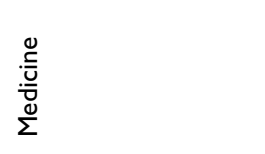 & 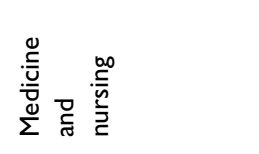 & 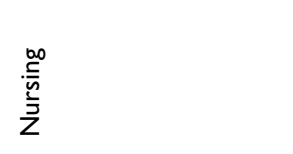 \\
\hline نे & 弚 & کొ & 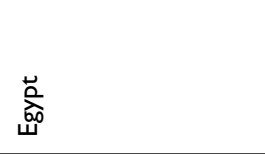 & 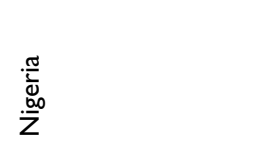 & 弚 \\
\hline 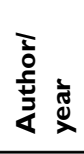 & 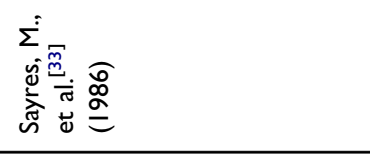 & 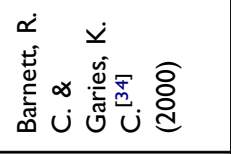 & 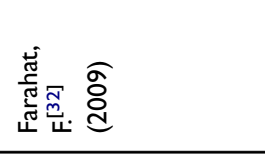 & 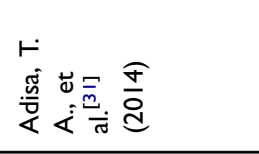 & 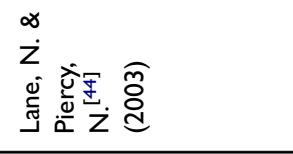 \\
\hline$\stackrel{\circ}{\mathbf{z}}$ & - & $N$ & $m$ & $\sigma$ & n \\
\hline
\end{tabular}




\begin{tabular}{|c|c|c|c|c|}
\hline 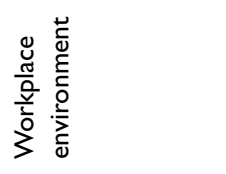 & 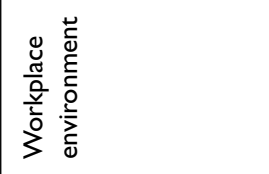 & 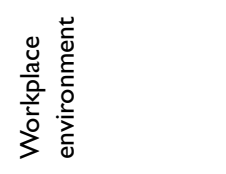 & 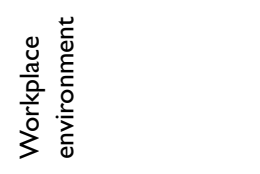 & 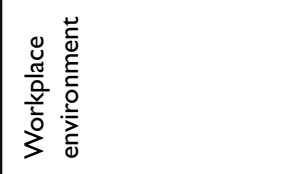 \\
\hline 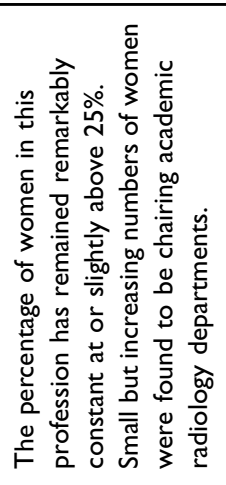 & 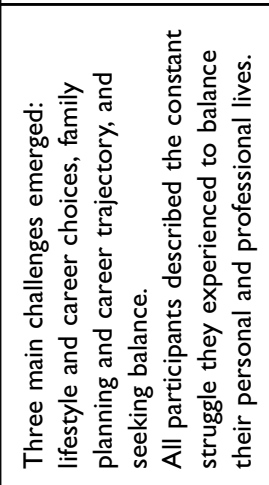 & 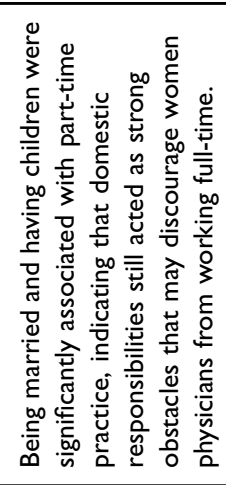 & 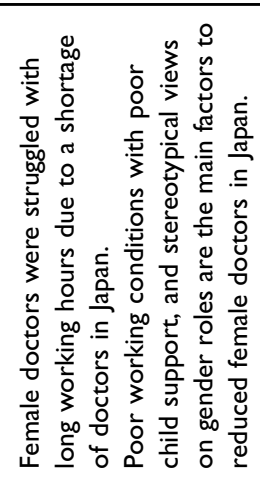 & 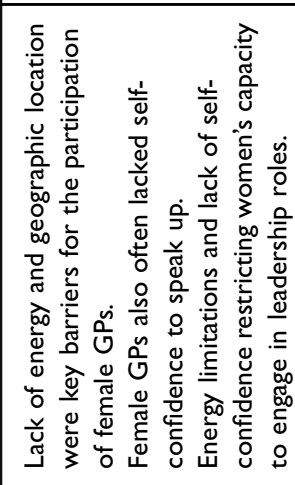 \\
\hline 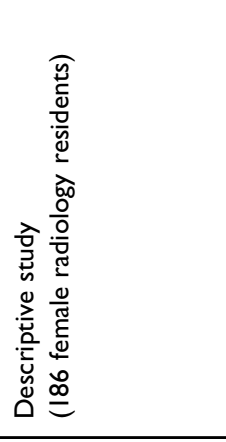 & 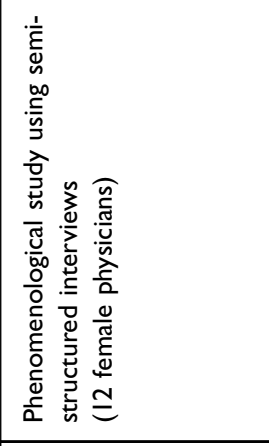 & 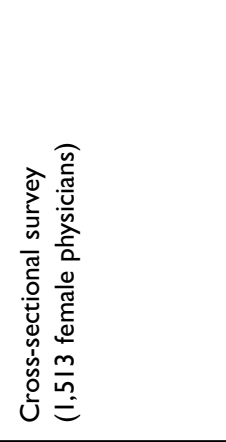 & 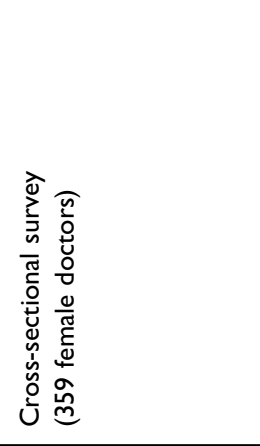 & 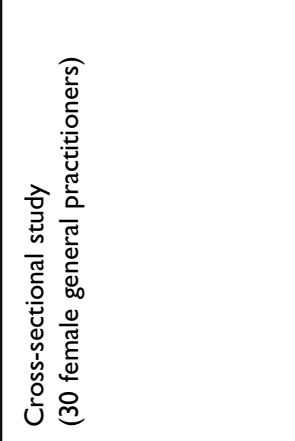 \\
\hline 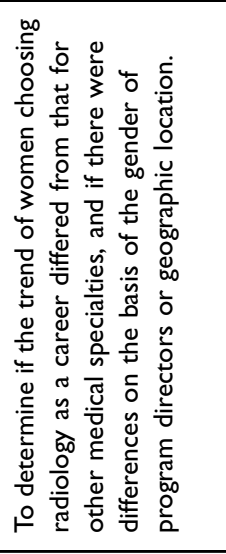 & 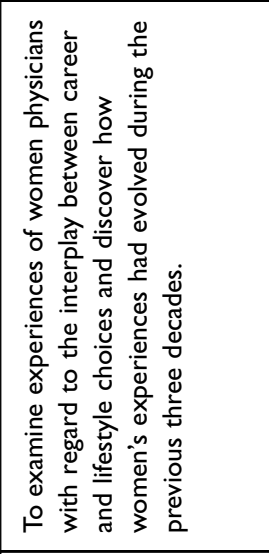 & 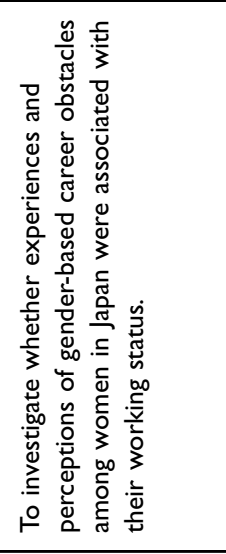 & 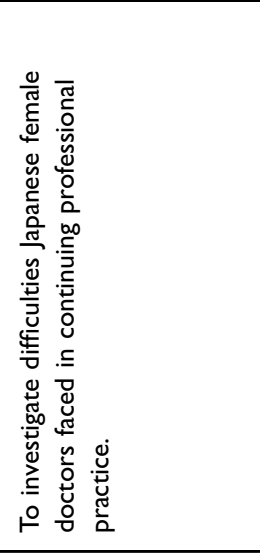 & 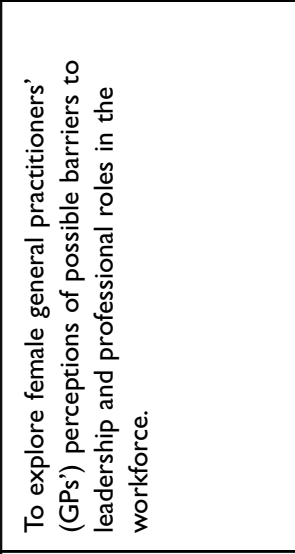 \\
\hline 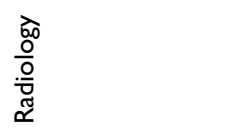 & 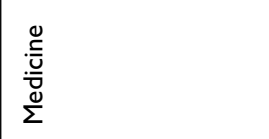 & 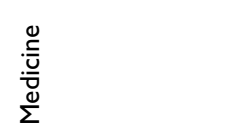 & 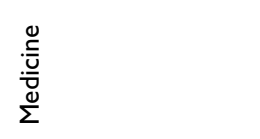 & 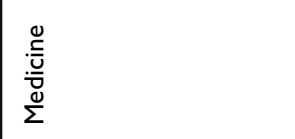 \\
\hline 离 & 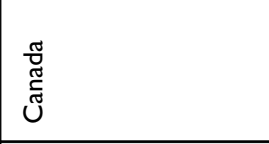 & 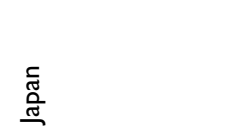 & 总 & 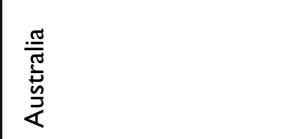 \\
\hline 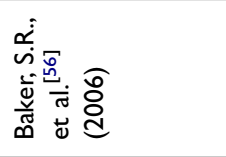 & 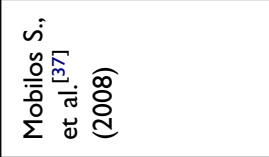 & 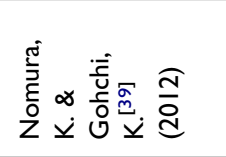 & 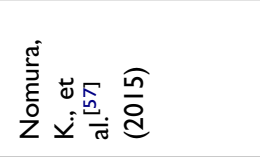 & 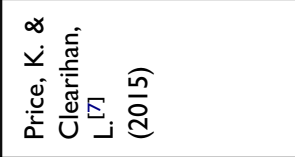 \\
\hline 0 & n & $\infty$ & $a$ & 으 \\
\hline
\end{tabular}




\begin{tabular}{|c|c|c|c|c|}
\hline 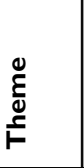 & 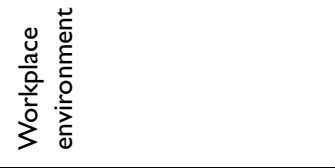 & 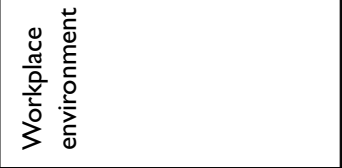 & 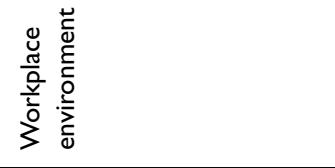 & 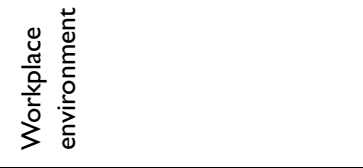 \\
\hline 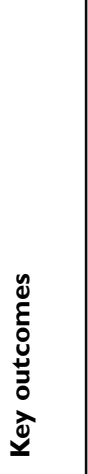 & 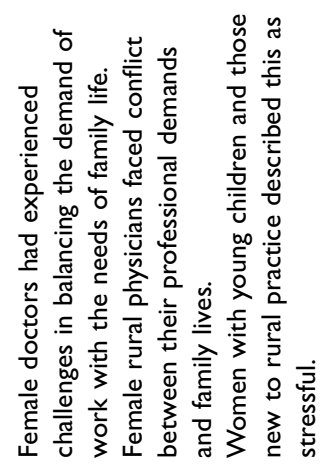 & 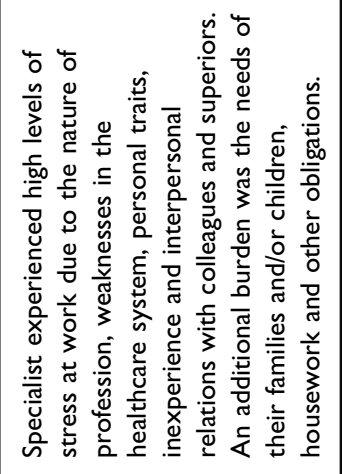 & 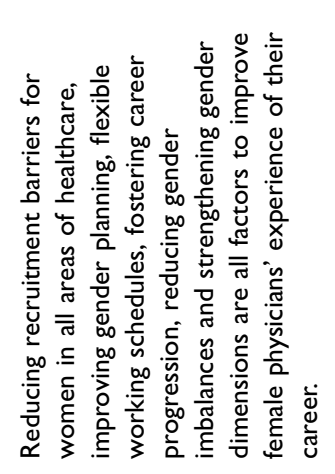 & 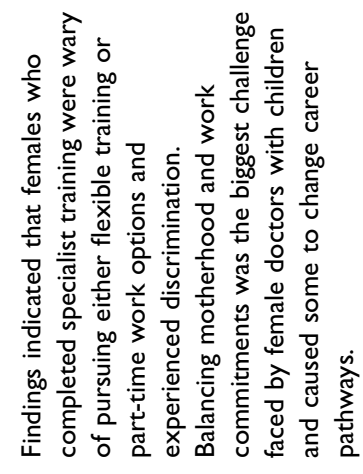 \\
\hline 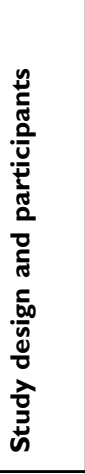 & 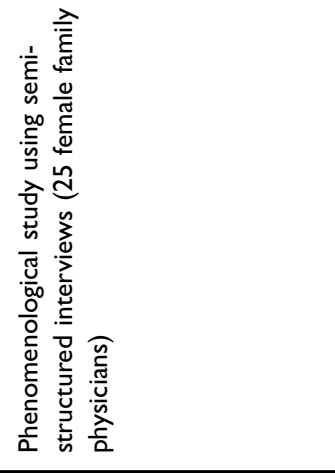 & 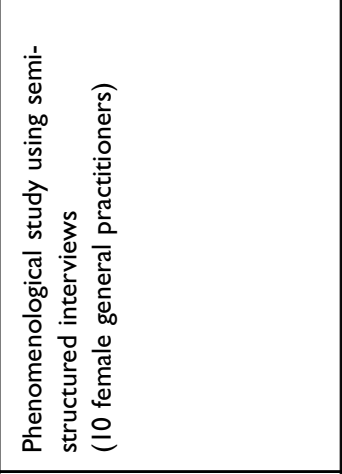 & 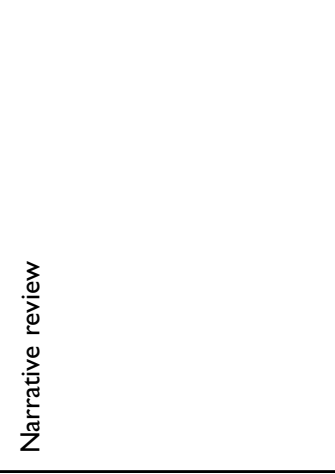 & 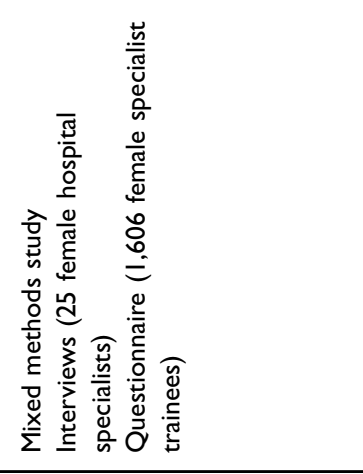 \\
\hline 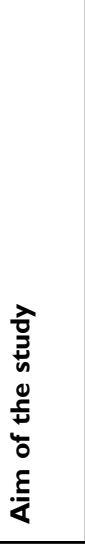 & 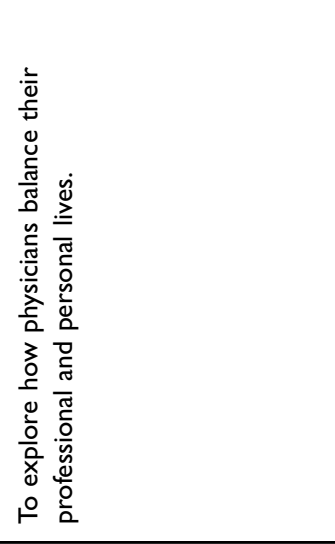 & 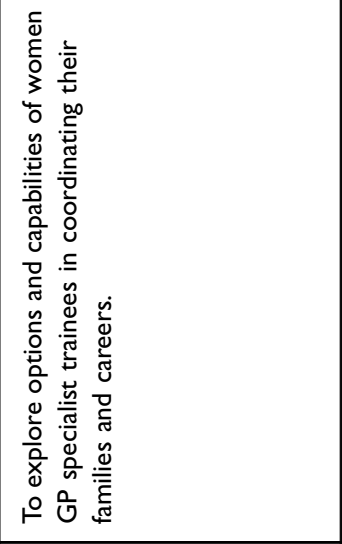 & 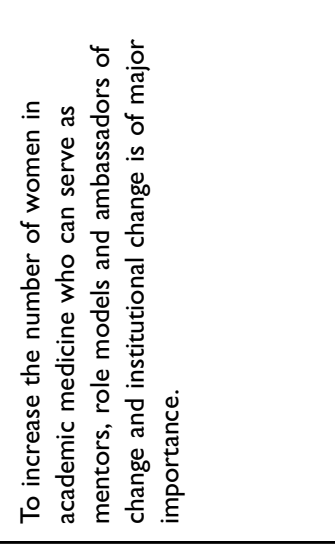 & 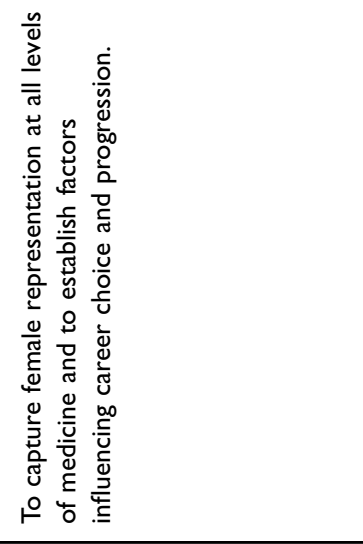 \\
\hline 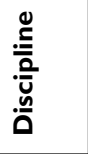 & 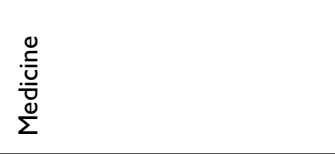 & 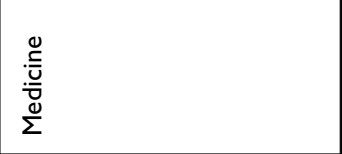 & 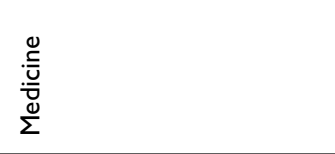 & 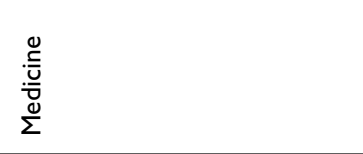 \\
\hline نे & ऽొ & 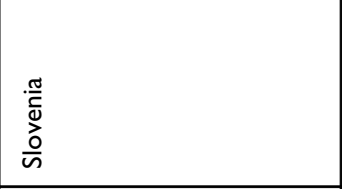 & 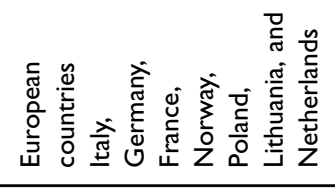 & 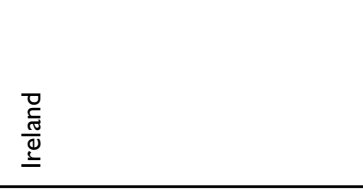 \\
\hline 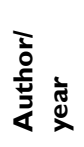 & 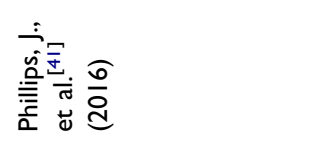 & 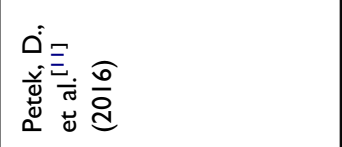 & 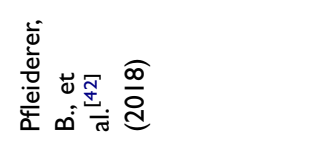 & 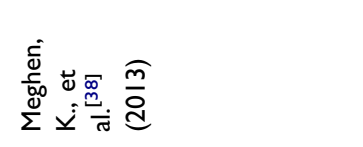 \\
\hline ¿̊ & $=$ & $\simeq$ & $\underline{m}$ & \pm \\
\hline
\end{tabular}




\begin{tabular}{|c|c|}
\hline 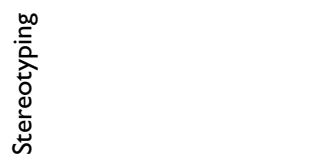 & 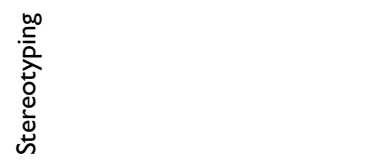 \\
\hline 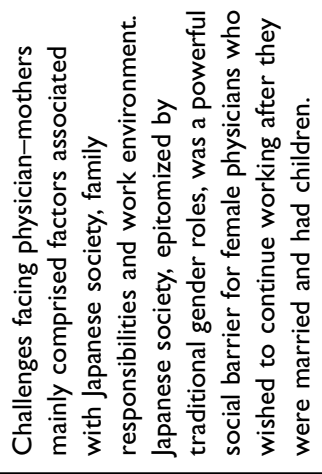 & 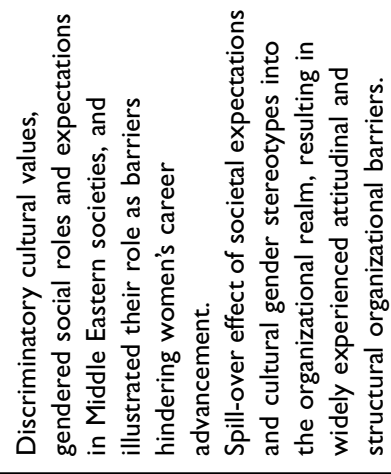 \\
\hline 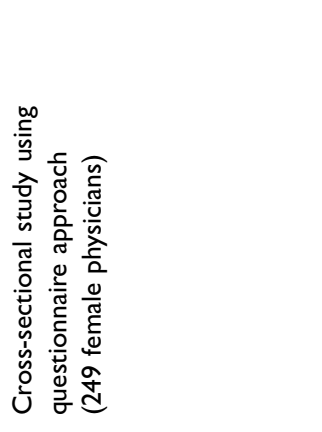 & 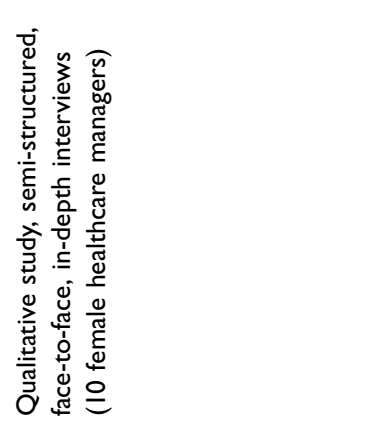 \\
\hline 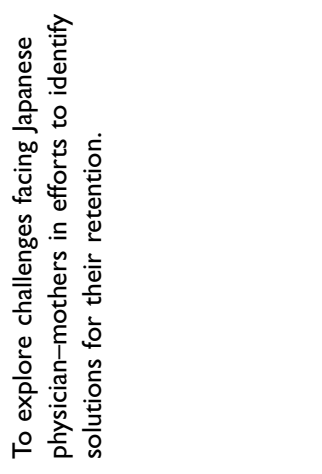 & 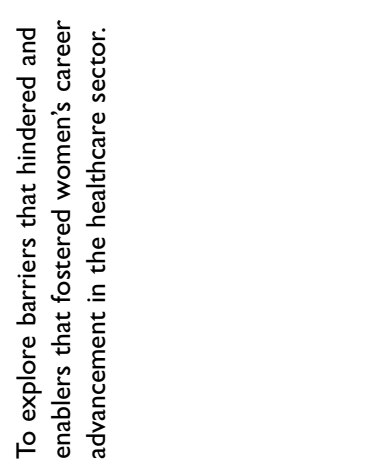 \\
\hline 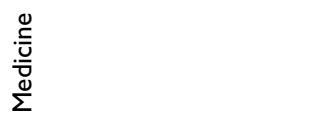 & 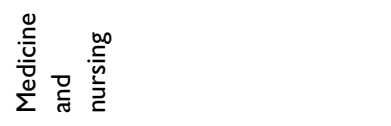 \\
\hline 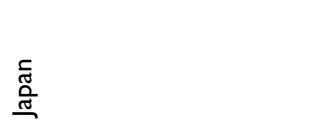 & 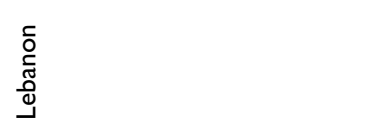 \\
\hline 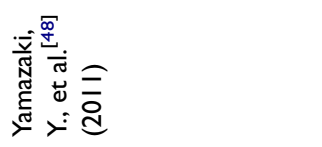 & 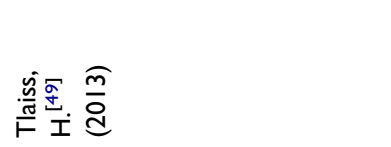 \\
\hline$\underline{\text { 느 }}$ & $\underline{\circ}$ \\
\hline
\end{tabular}

authorities came forward and drove an instrumental effort to establish change and different expectation settings for women. ${ }^{49}$

\section{Limitations and Future Research}

Although the scoping review yielded 16 articles, there are several limitations that should be declared. First, some articles or references may have been missed due to using specific MeSH-terms/keywords. Additionally, we searched five of the most important databases in the healthcare field so some articles might have been missed. To address these limitations, we employed strategies such as manual searching, grey literature searches and expert advice to ensure key information was included in this review. Finally, we limited our search to include only studies conducted in English so this might have led to missing some relevant studies in other languages. More research is needed to further investigate the themes raised in this study. For example, a theoretical framework that integrates the themes of this study with a theory such as glass ceiling, gendered organizations theory and institutional theory can be researched in the future to help improve the status of female healthcare professionals in their workplace.

\section{Conclusion}

This scoping review aimed to describe the challenges faced by female healthcare professionals in the workplace. The 16 articles yielded information categorized under three broad thematic headings - family responsibilities, workplace environment and stereotyping. Although separated by theme, there was an apparent link across the themes and articles reviewed. For example, the workplace environment, such as inadequate support for women, led to work-life imbalance and affected family responsibilities, whereas stereotyping and discrimination led to stress, low productivity and low life satisfaction. Low life satisfaction affects all functions of an individual, personally and professionally. Therefore, implementing strategies such as reduced work hours, flexible timing and part-time work may contribute to highly motivated women in the workplace, which will, in turn, enhance and support gender equality across healthcare organizations.

\section{Disclosure}

The authors report no conflicts of interest in this work. 


\section{References}

1. Heron A More women than ever are in the workfore but progress has been glacial; 2016. Available from: https://theconversation.com/ more-women-than-ever-are-in-the-workforce-but-progress-has-beenglacial-54893. Accessed February 19, 2019.

2. Australian Bureau of Statistics. Gender indicators, Australia, Sep 2018; 2018. Available from: http://www.abs.gov.au/ausstats/abs@. nsf/Lookup/by\%20Subject/4125.0 Sep\%202018 Main\% 20Features Economic\%20Security 4. Accessed February 17, 2019.

3. Bureau of labor statistics labor force statistics from the current population; 2019. Available from: https://www.bls.gov/cps/cpsaat18. htm. Accessed February 20, 2019.

4. Punshon G, Maclaine K, Trevatt P, Radford M, Shanley O, Leary A. Nursing pay by gender distribution in the UK - does the Glass Escalator still exist? Int J Nurs Stud. 2019;93:21-29. doi:10.1016/j. ijnurstu.2019.02.008

5. Barrett-Landau S, Henle S. Men in nursing: their influence in a female dominated career. J Leadersh Instr. 2014;13:10-13.

6. Canadian Institute for Health Information. A profile of physicians in Canada; 2017. Available from: https://www.cihi.ca/en/a-profile-ofphysicians-in-canada-2017. Accessed February 18, 2019.

7. Price K, Clearihan L Exploring female GPs' perceptions about medical leadership; 2015. Available from: https://search-informit-com-au. ezproxy.lib.monash.edu.au/fullText; dn=213668411833510;res= IELHEA. Accessed February 19, 2019.

8. Lantz PM. Gender and leadership in healthcare administration: 21 st century progress and challenges. $J$ Healthc Manag. 2008;53 (5):292-301. doi:10.1097/00115514-200809000-00004

9. EL-Sanabary N. The education and contribution of women health care professionals in Saudi Arabia: the case of nursing. Soc Sci Med J. 1993;37(11):1331-1343. doi:10.1016/0277-9536(93)90163-X

10. Schueller-Weidekamm C, Kautzky-Willer A. Challenges of work-life balance for women physicians/mothers working in leadership positions. Gend Med. 2012;9(4):244-250. doi:10.1016/j.genm.20 12.04.002

11. Petek D, Gajsek T, Petek Ster M. Work-family balance by women GP specialist trainees in Slovenia: a qualitative study. BMC Med Educ. 2016;16:31. doi:10.1186/s12909-016-0551-2

12. Feldman S. Female doctors by country, the statistics portal; 2018. Available from: https://www.statista.com/chart/14983/female-doctors -by-country/. Accessed February 18, 2019.

13. Treister-Goltzman Y, Peleg R. Female physicians and the work-family conflict. Isr Med Assoc J 2016;18(5):261-266.

14. Batchelor H Women under represented in senior pharmacy and NHS roles the pharmaceutical journal; 2018. Available from: https://www. pharmaceutical-journal.com/news-and-analysis/news/women-

underrepresented-in-senior-pharmacy-and-nhs-roles/20204515.arti cle?firstPass=false. Accessed February 17, 2019.

15. Al-Riyami M, Fischer I, Lopez V. Nurses' perceptions of the challenges related to the Omanization policy. Int Nurs Rev. 2015;62 (4):462-469. doi:10.1111/inr.12221

16. Alilu L, Zamanzadeh V, Fooladi MM, Valizadeh L, Habibzadeh H. Towards an understanding of clinical nurses challenges that leads intention to leave. Acta Paulista De Enfermagem. 2016;29 (5):534-541. doi:10.1590/1982-0194201600074

17. Sells JM, Sells CJ. Pediatrician and parent: a challenge for female physicians. Pediatrics. 1989;84(2):355-361.

18. Azeem SM, Akhtar N. The influence of work life balance and job satisfaction on organizational commitment of healthcare employees. Int J Hum Resour Stud. 2014;4(2):18. doi:10.5296/ijhrs.v4i2.5667

19. Desai T, Ali S, Fang X, Thompson W, Jawa P, Vachharajani T. Equal work for unequal pay: the gender reimbursement gap for healthcare providers in the United States. Postgrad Med J. 2016;92 (1092):571-575. doi:10.1136/postgradmedj-2016-134094
20. Hong Lu K, Barriball L, Zhang X, While A. Job satisfaction among hospital nurses revisited: a systematic review. Int J Nurs Stud. 2011;49:1017-1038. doi:10.1016/j.ijnurstu.2011.11.009

21. Mackusick C, Minick P. Why are nurses leaving? Findings from an initial qualitative study on nursing attrition. Medsurg Nurs. 2010;19 (6):335-341.

22. Younas M, Rattani S. Harassment: a challenge at workplace. Imanagers $J$ Nurs. 2014;4(1):35-39. doi:10.26634/jnur.4.1.2630

23. Kerr HL, Armstrong LA, Cade JE. Barriers to becoming a female surgeon and the influence of female surgical role models. Postgrad Med J. 2016;92(1092):576-580. doi:10.1136/postgradmedj-2015133273

24. Ali A, Subhi Y, Ringsted C, Konge L. Gender differences in the acquisition of surgical skills: a systematic review. Surg Endosc. 2015;29(11):3065-3073. doi:10.1007/s00464-015-4092-2

25. Arksey H, O'Malley L. Scoping studies: towards a methodological framework. Int J Soc Res Methodol. 2005;8(1):19-32. doi:10.1080/ 1364557032000119616

26. Pham MT, Rajić A, Greig JD, Sargeant JM, Papadopoulos A, McEwen SA. A scoping review of scoping reviews: advancing the approach and enhancing the consistency. Res Synth Methods. 2014;5 (4):371-385. doi:10.1002/jrsm.1123

27. Grant MJ, Booth A. A typology of reviews: an analysis of 14 review types and associated methodologies. Health Info Libr J. 2009;26 (2):91-108. doi:10.1111/j.1471-1842.2009.00848.x

28. Auerbach DI, Buerhaus PI, Staiger DO. Registered nurse supply grows faster than projected amid surge in new entrants ages 23-26. Health Aff. 2011;30(12):2286-2292. doi:10.1377/hlthaff.2011.0588

29. Elston M women and medicine: the future; 2009. Available from: http://www.learning.ox.ac.uk/media/global/wwwadminoxacuk/local sites/oxfordlearninginstitute/documents/overview/women_and_medi cine.pdf. Accessed February 19, 2019.

30. Al-Asfour A, Tlaiss HA, Khan SA, Rajasekar J. Saudi women's work challenges and barriers to career advancement. Career Dev Int. 2017;22(2):184-199. doi:10.1108/CDI-11-2016-0200

31. Adisa TA, Mordi C, Mordi T. The challenges and realities of work-family balance among Nigerian female doctors and nurses. Economic Insights - Trends Challenges. 2014;66(3):23-37.

32. Farahat F. Challenges facing female physicians in Egypt. Arch Environ Occup Health. 2009;64(2):121-127. doi:10.3200/ AEOH.64.2.121-128

33. Sayres M, Wyshak G, Denterlein G, Apfel R, Shore E, Federman D. Pregnancy during residency. $N$ Engl J Med. 1986;314(7):418-423. doi:10.1056/NEJM198602133140705

34. Barnett RC, Gareis KC. Reduced-hours job-role quality and life satisfaction among married women physicians with children. Psychol Women Q. 2000;24(4):358-364. doi:10.1111/j.14716402.2000.tb00218.x

35. Victorian Equal Opportunity and Human Right Commission. Pregnancy and work: know your right and obligations. Victorian Equal Opportunity and Human Rights Commission; 2017. Available from: https://www.humanrightscommission.vic.gov.au. Accessed February 21, 2019.

36. Australian Human Rights Commission. Pregnancy guidelines 2001. Australian Human Rights Commission; 2001. Available from: https:// www.humanrights.gov.au/publications/pregnancy-fact-sheet. Accessed February 19, 2019.

37. Mobilos S, Chan M, Brown JB. Women in medicine: the challenge of finding balance. Can Fam Physician. 2008;54(9):1285-6.e5.

38. Meghen K, Sweeney C, Linehan C, O'Flynn S, Boylan G. Women in hospital medicine: facts, figures and personal experiences. Ir Med J. 2013;106(2):39-42.

39. Nomura K, Gohchi K. Impact of gender-based career obstacles on the working status of women physicians in Japan. Soc Sci Med. 2012;75 (9):1612-1616. doi:10.1016/j.socscimed.2012.07.014 
40. Nomura K, Yamazaki Y, Gruppen L, Horie S, Takeuchi M, Illing J. The difficulty of professional continuation among female doctors in Japan: a qualitative study of alumnae of 13 medical schools in Japan. BMJ Open. 2015;5(3):(no pagination)(e005845).

41. Phillips J, Hustedde C, Bjorkman S, et al. Rural women family physicians: strategies for successful work-life balance. Ann Fam Med. 2016;14(3):244-251. doi:10.1370/afm.1931

42. Pfleiderer B, Bortul M, Palmisano S, Rodde S, Hasebrook J. Improving female physician's careers in academic medicine: chances and challenges. Best Pract Res Clin Anaesthesiol. 2018;32(1):15-23.

43. Morley L. Lost leaders: women in the global academy. High Educ Res Dev. 2014;33(1):114-128. doi:10.1080/07294360.2013.864611

44. Lane N, Piercy NF. The ethics of discrimination: organizational mindsets and female employment disadvantage. J Bus Ethics. 2003;44(4):313-325. doi:10.1023/A:1023644602447

45. Weil PA, Mattis MC. To shatter the glass ceiling in healthcare management: who supports affirmative action and why? Health Serv Manage Res. 2003;16:224-233. doi:10.1258/095148403322488928

46. Eiser BJ, Morahan P. Fixing the system: breaking the glass ceiling in health care. Leadership in Action. 2006;26(4):8-13. doi:10.1002/ lia. 1171

47. Barsh J, Cranston S, Craske RA. Centered leadership: how talented women thrive. McKinsey Q. 2008;4:35-48.

48. Yamazaki Y, Kozono Y, Mori R, Marui E. Difficulties facing physician mothers in Japan. Tohoku J Exp Med. 2011;225(3):203-209. doi:10.1620/tjem.225.203

49. Tlaiss HA. Women in healthcare: barriers and enablers from a developing country perspective. Int $J$ Health Policy Manag. 2013;1(1):23-33. doi:10.15171/ijhpm.2013.05
50. Hodges A Opportunities for women: challenging harmful social norms and gender stereotypes to unlock women's potential; 2017. Available from: https://www.unilever.com/Images/unileveropportunities-for-women_tcm244-500987_en.pdf. Accessed February 25, 2019.

51. Kollmeyer C. Family structure, female employment, and national income inequality: a cross-national study of 16 western countries. Eur Sociol Rev. 2012;29(4):816-827. doi:10.1093/esr/jcs060

52. Alotaibi F, Cutting R, Morgan J. A critical analysis of the literature in women's leadership in Saudi Arabia. Int J Bus Adm Res. 2017;3 (1):29. doi:10.24178/ijbamr.2017.3.1.29

53. Okura Gagné N. Neoliberalism at work: corporate reforms, subjectivity, and post-Toyotist affect in Japan. Anthropol Theory. 2019;1463499618807294.

54. Metcalfe BD. Women, management and globalization in the Middle East. J Bus Ethics. 2008;83(1):85-100. doi:10.1007/s10551-0079654-3

55. Echabe AE. Role identities versus social identities: masculinity, femininity, instrumentality and communality. Asian J Soc Psychol. 2010;13(1):30-43. doi:10.1111/j.1467-839X.2010.01298.x

56. Baker SR, Barry M, Chaudhry H, Hubbi B. Women as radiologists: are there barriers to entry and advancement? J Am Coll Radiol. 2006;3(2):131-134. doi:10.1016/j.jacr.2005.10.001

57. Nomura K, Yamazaki Y, Gruppen LD, Horie S, Takeuchi M, Illing J. The difficulty of professional continuation among female doctors in Japan: a qualitative study of alumnae of 13 medical schools in Japan BMJ Open. 2015;5(3):e05845. doi:10.1136/bmjopen-2014-005845
Journal of Multidisciplinary Healthcare

\section{Publish your work in this journal}

The Journal of Multidisciplinary Healthcare is an international, peerreviewed open-access journal that aims to represent and publish research in healthcare areas delivered by practitioners of different disciplines. This includes studies and reviews conducted by multidisciplinary teams as well as research which evaluates the results or conduct of such teams or healthcare processes in general. The journal covers a very wide range of areas and welcomes submissions from practitioners at all levels, from all over the world. The manuscript management system is completely online and includes a very quick and fair peer-review system. Visit http://www.dovepress.com/testimonials. php to read real quotes from published authors. 